\title{
CORRIGENDUM
}

\section{Development of a Listeria monocytogenes-based vaccine against hepatocellular carcinoma}

Y Chen, D Yang, S Li, Y Gao, R Jiang, L Deng, FR Frankel and B Sun

Oncogene (2012) 31, 4810; doi:10.1038/onc.2012.430

Correction to: Oncogene (2012) 31, 2140-2152; doi:10.1038/ onc.2011.395; published online 19 September 2011

Since the publication of the above manuscript, the authors have identified two errors in the figures (Figure 4a and Figure 7a). These errors were inadvertently introduced during figure preparation. The revised version of Figure $4 a$ and Figure $7 a$ are now given below. The mistake in Figure $7 a$ also affects the results of the original published manuscript (page 2146, line 1-2). The corrected results are $4.91 \pm 0.56 \%$ prophylactic model, $6.914 \pm 0.54 \%$ therapeutic model and $13.96 \pm 1.74 \%$ no treatment.

The authors sincerely apologize for the error, and regret any confusion or inconvenience it may have caused. a
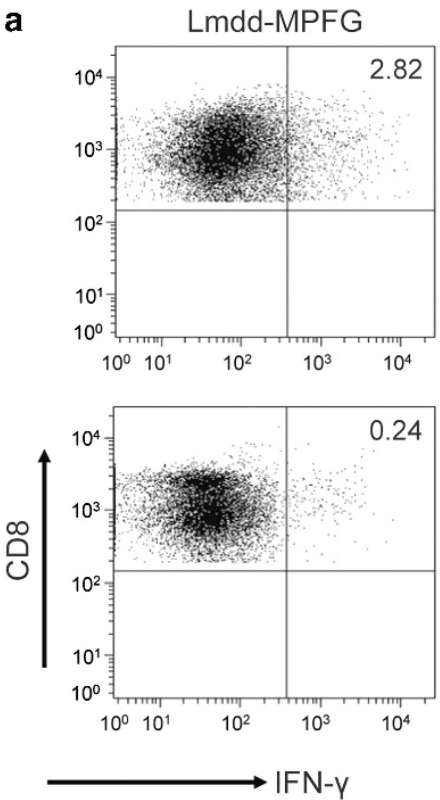

Lmdd-A2
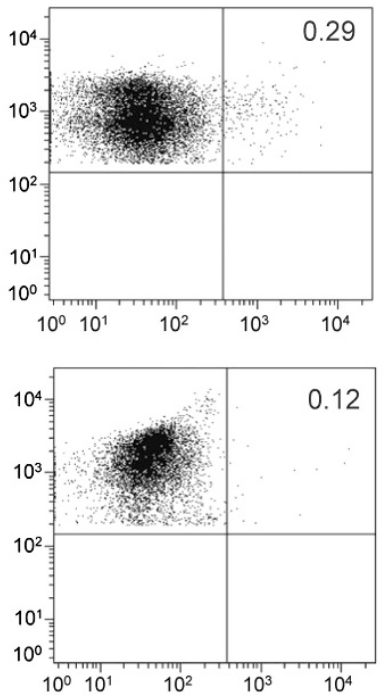

Naive mice
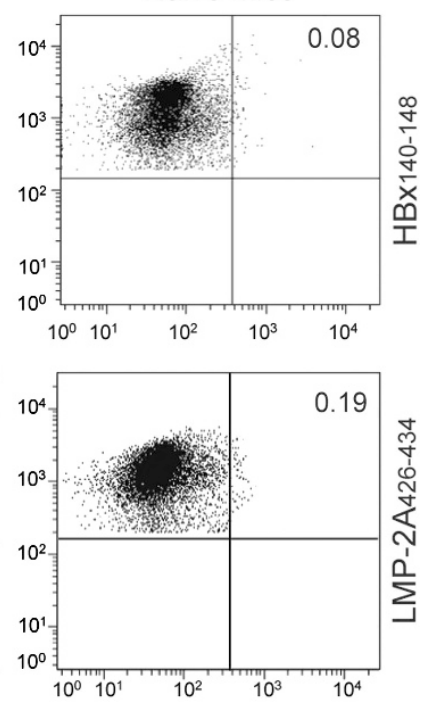

Figure 4a.
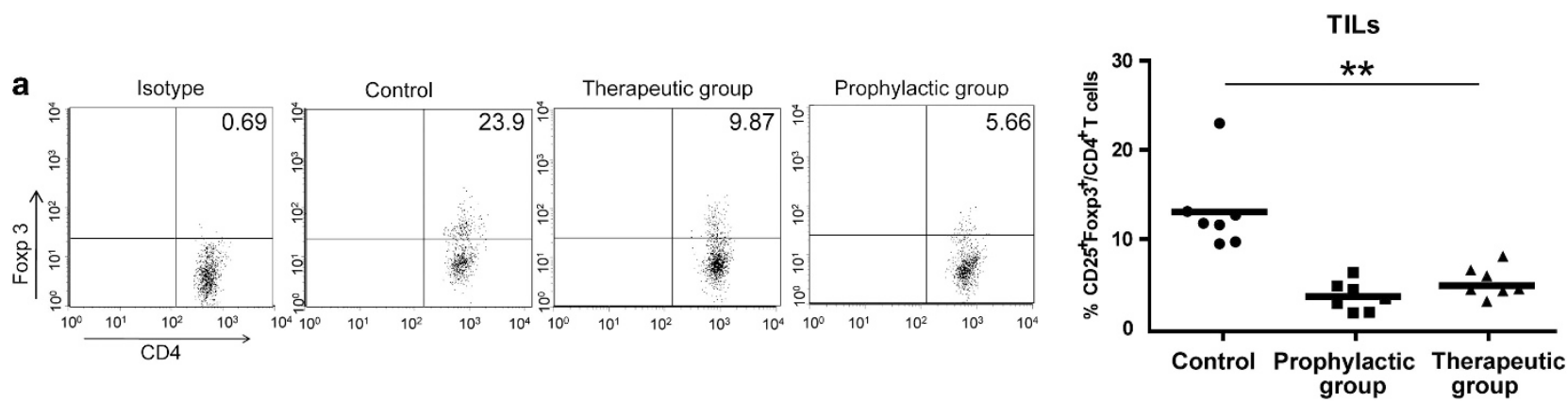

Figure $7 a$. 